depletion of the liver glycogen and the accompanying hypoglycaemia here observed were not the result of the special derangement of carbohydrate metabolism in endotoxaemia. Moreover, the fact that the characteristic leucopenia in response to shock-dose of endotoxin was not observed indicated that endotoxins or macromolecular tissue substances did not participate in inducing the development of the 'shock-inducing factor'. In this respect the endotoxin hypothesis of Fine et al. ${ }^{3}$ for the irreversible haemorrhagic shock does not seem acceptable.

The 'shock-inducing factor' was not detected either in plasma or in the liver extract when the animals succumbed to respiratory failure before marked 'up-take' supervened. When the adrenalectomized dogs were treated with glucocorticoids the tendency to hypoglycaemia did not proceed, so much within the hypotensive period of $5 \mathrm{~h}$ and the 'shock-inducing factor' was not found in detectable amounts in the plasma. In the presence of glycocorticoids, therefore, the anoxic deterioration of the hepatic function leading to the glycogen depletion and to the liberation of the 'shock-inducing factor' seemed to be markedly ameliorated. The significance of glucocorticoids was also obvious in their central analeptic action ${ }^{4}$ preventing the early onset of respiratory failure. The fact that glucocorticoids could not prevent the action of the 'shock-inducing factor' once liberated, as was elear in the transfusion experiments on intact dogs, might suggest their applicability to haemorrhagic shock is limited.

In passing, it may be noted that Wiggers ${ }^{5}$, observing the progress of irreversible haemorrhagic shock after restitution of blood volume by re-infusion of all the withdrawn blood (normovolemic shock), mentioned that hepatic resistance contrary to all other organs examined increases markedly and is chiefly responsible for the elevated portal pressure. This might perhaps indicate the participation of the 'shock-inducing factor' shown hore, although the amounts liberated are too small to be detected by the passive transfer technique because of the presence of adrenal cortex. Why clear experimental evidence has not been hitherto available that endogenous toxins are concerned as a cause or contributory factor in shock might be due to the fact that the experiments have been exclusively made on intact animals. The significance of the 'shock-inducing factor' in the development of the irreversibility of shock in intact animals will be further investigated.

\section{Tokuro Fukuda}

Department of Physiology,

Chiba University School of Medicine, Japan.

${ }^{1}$ Fukuda, T., Kobayashi, T., and Okada, M., Nature, 204, 585 (1964).

${ }^{2}$ Fukuda, T., Okada, M., and Kobayashi, T., Jap. J. Physiol., 14, 560 (1964).

${ }^{3}$ Schweinburg, F. B., and Fine, J., J. Exp. Med.,112, 793 (1960).

${ }^{4}$ Fukuda, T., and Koyama, T., Jap. J. Physiol.,12, 176 (1962).

${ }^{5}$ Wiggers, C. J., Physiology of Shock, 248 (Harvard Univ. Press, 1950).

\section{Oral Treatment of Pernicious Anaemia}

HeATHCOTE and Mooney ${ }^{1}$ reported in this journal their clinical results from treating two cases of pernicious anaemia with a vitamin $\mathbf{B}_{12}$ glutamic acid mixture, and we published ${ }^{2}$ our own results of Schilling tests with and without L-glutamic acid in patients with pernicious anaemia. Our results showed that glutamic acid does not in general increase the absorption of vitamin $\mathbf{B}_{12}$ measured by the Schilling test. In their reply ${ }^{3}$ Mooney and Heathcote disregarded our results, doubting whether the Schilling test has in fact any physiological merit at all. Although we cannot concur in their opinion of the Schilling test, we decided to investigate the problem from another aspect as well.

The essential weakness in the study by Heathcote and Mooney, in our opinion, was the too short control period

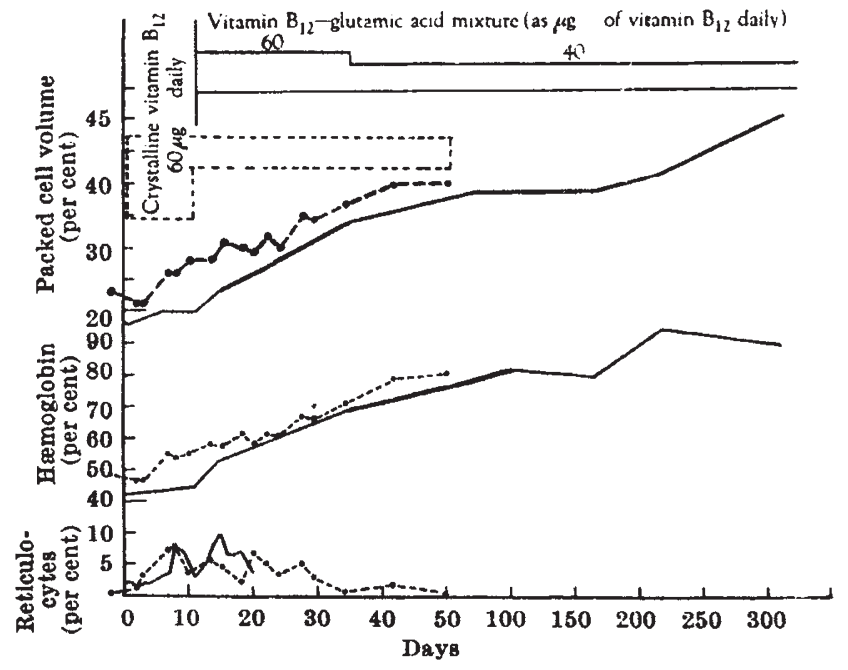

Fig. 1

with oral vitamin $\mathrm{B}_{12}$ alone. It was just this point which originally made us doubt the significance of glutamic acid. However, as Heathcote and Mooney emphasize the importance of the type of test they used, we treated one pernicious anaemia patient in the same manner, that is, with $60 \mu \mathrm{g}$ of vitamin $\mathbf{B}_{12}$ daily orally, except that the glutamic acid additive was omitted. The result is seen in Fig. 1. The development of the blood picture of our case is traced as a dotted line on a copy of Heatheote and Mooney's Fig. 1 (ref. 1). We followed our case for 50 days only, but it is quite apparent that the increase in haemoglobin and packed cell volume is as good as in their case. This we in fact expected, but in addition the reticulocyte curve displayed several successive peaks. We thus obtained a completely similar haematological progress by prolonging the mere vitamin $\mathbf{B}_{12}$ 'control period' sufficiently.

As, according to Ross et al. ${ }^{4}$, about 1 per cent of an oral vitamin $\mathbf{B}_{12}$ dose is absorbed even without the intrinsic factor, about $0.6 \mu \mathrm{g}$ daily would be absorbed from $60 \mu \mathrm{g}$. This is practically the same as the $1 \mu \mathrm{g}$ which, given parenterally, suffices in the opinion of Bethel et al. ${ }^{5}$ to cause remission in pernicious anaemia. It is understandable, then, that the $60 \mu \mathrm{g}$ dose sufficed, completely independent of the concomitant administration of glutamic acid.

In our opinion, therefore, Heathcote and Mooney's work does not prove that oral administration of vitamin $B_{12}$ is more efficacious in cases of pernicious anaemia when administered together with glutamic acid. That the same therapeutic result may in fact be achieved with vitamin $B_{12}$ alone, as we have now shown, could have been presupposed from the results of our earlier Schilling tests ${ }^{2}$.

Ilmari Palva Olli HeinivaARa

Second Medical Department,

University of Helsinki, Finland.

${ }^{1}$ Heathcote, J. G., and Mooney, F. S., Nature, 193, 380 (1962).

${ }^{2}$ Heinivaara, O., and Palva, I., Nature, 199, 289 (1963).

${ }^{3}$ Mooney, F. S., and Heathcote, J. G., Nature, 199, 290 (1963).

${ }^{4}$ Ross, G. I. M., Mollin, D. L., Cox, E. V., and Ungley, C. C., Blood, 9, 473 (1954) 5 Bethel, F. H., Meyers, M. C., and Neligh, R. B., J. Lab. Clin. Med., 33, 477
(1948).

IT will not surprise many workers in the $\mathbf{B}_{12}$ field to read that Dr. Heinivaara and Dr. Palva have obtained a remission over a period of 50 days in one case of perni- 